\title{
A AUTOCOMPOSIÇÃO NAS AÇÕES DE FAMÍLIA DE ACORDO COM O NOVO CPC
}

\author{
Bruno Coelho Gonçalves, Juliane Nagafugi de Souza Costa
}

Universidade do Oeste Paulista - UNOESTE, curso de Direito, Presidente Prudente, SP. E-mail: julianenagafugi@gmail.com

\section{RESUMO}

O estudo em questão objetiva evidenciar e analisar a incidência da conciliação e mediação no Poder Judiciário Nacional. Os meios alternativos de composição de conflitos mostram-se como uma escolha inteligente e ágil para por fim à lide. Para as ações de família no novo CPC, o legislador aderiu a um procedimento especial que estimula explicitamente a autocomposição, através da mediação. Neste sentido, a presente pesquisa também será voltada a analisar esse instituto, que se mostra como uma das melhores alternativas quando o litígio se dá no âmbito familiar, visando resolvê-lo a partir do diálogo entre as partes e proporcionando o restabelecimento do alicerce familiar, base elementar da sociedade protegida constitucionalmente.

Palavras-chave: Autocomposição, Instrumentos alternativos, Mediação, Ações de família, Novo CPC.

\section{THE SELF-COMPOSITION IN FAMILY ACTIONS ACCORDING TO THE NEW CPC}

\section{ABSTRACT}

The study in question aims to evidence and analyze the incidence of conciliation and mediation in the National Judiciary. The alternative ways of composition of conflicts are shown as an intelligent and agile choice for finally to it participates in her. For the family actions in new CPC, the legislator adhered to a special procedure that it stimulates the autocomposição explicitly, through the mediation. In this sense, to present he/she researches also be returned to analyze that institute, that is shown as one of the alternative best when the litigation feels in the family extent, seeking to solve him/it starting from the dialogue among the parts and providing to re-establishment of the family foundation, elementary base of the society protected constitutionally.

Keywords: Autocomposição, Alternative instruments, Mediation, Family actions, New CPC.

\section{INTRODUÇÃO}

São instrumentos alternativos para a resolução de conflitos os institutos da mediação e da conciliação, que primam por revisitar as partes litigantes na busca de uma solução plausível, sem a necessidade de uma batalha judicial. Ou seja, trata-se de uma forma de compor a lide que descarta a esfera processual.

$\mathrm{Na}$ realidade atual, tais mecanismos tornaram-se a alternativa do legislador, visto que o descrédito pelo Poder Judiciário vem crescendo, decorrência de sua lentidão e grande burocratização. Tem-se a mediação e a conciliação, ainda, como os métodos adequados para resolver os conflitos preservando os relacionamentos (CAPELLETTI, 1988, p. 26/27), resultado tido como inalcançável por meio de um trâmite judicial.

O Diploma Processual Civil, aprovado em 2015, incentiva a aplicação dos meios alternativos de composição das lides, ampliando e antecipando (art. 3을 a sua aplicação no processo, além de 
instituí-lo em procedimentos especiais de forma incisiva, como é o caso das Ações de Família.

É passível de afirmação que mais do que um mero estímulo, o novo Código visa inserir uma cultura da autocomposição, além de enfatizar ser dever de todos os sujeitos processuais colaborarem mutuamente, visando efetividade na resolução da lide (art. 60). Segundo Didier Jr.:

o Poder Legislativo tem reiteradamente incentivado a autocomposição, com a edição de diversas leis neste sentido. O CPC ratifica e reforça essa tendência: a) dedica um capítulo inteiro para regular a mediação e a conciliação (arts. 165-175); b) estrutura o procedimento de modo a pôr a tentativa de autocomposição com ato anterior ao oferecimento da defesa pelo réu (art. 334 e 695); c) permite a homologação judicial de acordo extrajudicial de qualquer natureza (art. 515, III; art. 725, VIII); d) permite que, no processo (art. 515, §2ㅇ); e) permite acordos processuais (sobre o processo, não sobre o objeto do litígio) atípicos (art. 190). (DIDIER JR., 2016, p. 271).

Já em 2010, a Resolução no. 125 do Conselho Nacional de Justiça (CNJ) reconheceu que o encaminhamento adequado das causas a meios consensuais configura política pública, ou seja, devendo a via alternativa de composição de conflitos ser sempre buscada. Mas foi o novo Código de Processo Civil que apareceu como marco da mediação e da conciliação, mostrando a importância outrora revelada. No mesmo contexto, possibilitou-se a elaboração de uma lei específica disciplinando a mediação entre particulares e no âmbito da administração pública - Lei no 13.140 , de 26 de junho de 2015.

Desse modo, evidencia-se o incentivo do legislador à utilização dos meios alternativos de resolução de conflitos, em substituição à via judicial, especialmente nas Ações de Família, através do rito diferenciado adotado no novo Código de Processo Civil (2015).

Para tanto, objetiva-se com o presente estudo analisar o instituto da mediação, que se mostra como uma das melhores alternativas quando o litígio se dá no âmbito familiar, visando resolvê-lo a partir do diálogo entre as partes e proporcionando o restabelecimento do alicerce familiar.

\section{METODOLODIA}

O estudo se vale do método dedutivo, dialético e empírico. Utilizou-se de levantamento bibliográfico, como livros de doutrina, artigos de revistas especializadas e demais documentos que se mostraram úteis e concernentes ao tema, além de pesquisa jurisprudencial e legislativa acerca do objeto do estudo, no intuito de cumprir com o objetivo proposto.

\section{RESULTADO}

Tendo em vista a jovialidade dos institutos nas Justiças Estaduais, a conciliação e a Mediação já possuem números positivos no judiciário brasileiro, conforme se verifica em pesquisa realizada pelo Conselho Nacional de Justiça - CNJ, em 2017. 
FIGURA 1

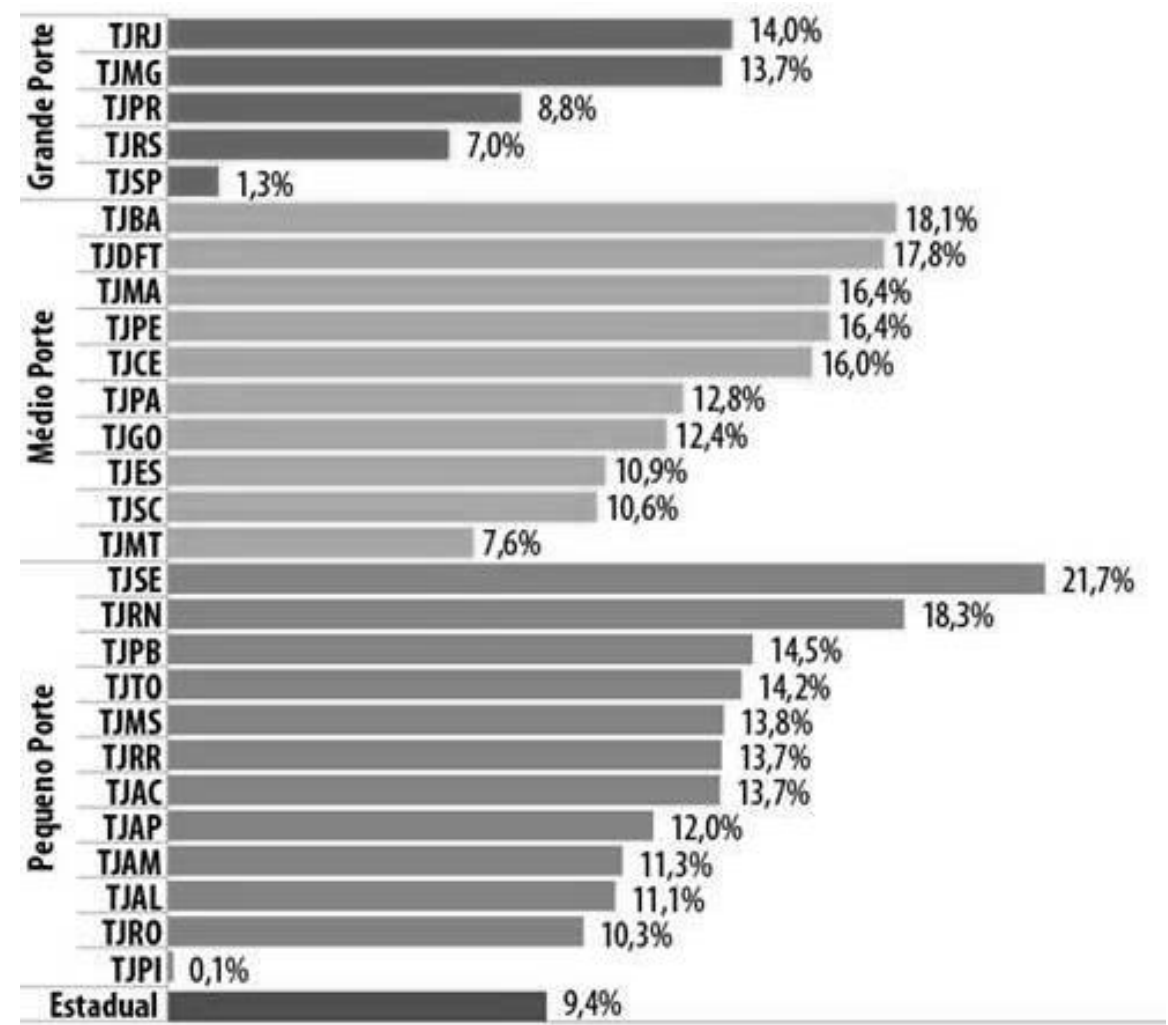

Índices da Conciliação e da Mediação nos Tribunais de Justiça do Brasil Fonte: Conselho Nacional de Justiça (2017).

Insta salientar que os procedimentos autocompositivos que atendem às Ações de Família, se comportam como adequados a tais situações, o que se coaduna com os recentes números da conciliação e da medição por todo o território nacional.

\section{DISCUSSÃO}

Das inúmeras inovações que a Lei 13.105 de 16 de março de 2015 comportou ao ordenamento jurídico brasileiro, uma que merece destaque é a previsão do tratamento das Ações de Família, dentro do livro dos procedimentos especiais, mais precisamente disposto nos artigos 693 a 699.

Segundo entendimento de Humberto Theodoro, essa novidade:

acolhe pretensão daqueles que militam no Direito de Família, os quais entendem que nele se discutem questões relevantes e de complexa resolução, que merecem maior atenção, não apenas porque envolvem a vida, a intimidade e a dignidade das pessoas que estão diretamente vinculadas ao litígio, mas também de seus familiares (THEODORO JUNIOR, 2016, p.367).

A família, protegida constitucionalmente pelo Estado (CF, art. 226, caput), é garantidora de assistência na pessoa de cada um de seus indivíduos integrantes.

No mesmo enfoque, a Constituição Federal de 1988, reconhece a união estável e aos núcleos monoparentais, como sendo entidades familiares (CF, art. 226, §§ 3으, 4ํ, 8ㅇ).

Hodiernamente, a Suprema Corte Brasileira entendeu não haver distinções entre as instituições família e entidade familiar, que nos dizeres pontuais de Humberto Theodoro, nos advertem que: 
o fato de o artigo constitucional fazer referência à família, em alguns dispositivos, e à entidade familiar, em outros, ensejou interpretações no sentido de que poderiam se referir a institutos distintos. Além disso, começaram a surgir ações atinentes às relações homoafetivas, temas que foram levados à apreciação do STF.

Em maio de 2011, o Tribunal Pleno julgou procedente a ADPF 132/RJ, para reconhecer que a Constituição federal "não empresta ao substantivo 'família' nenhum significado ortodoxo ou da própria técnica jurídica". Contextualizou o termo em "seu coloquial ou proverbial significado de núcleo doméstico, pouco importando se formal ou informalmente constituída, ou se integrada por casais heteroafetivos ou por pares homoafetivos". E rechaçou qualquer diferenciação, decidindo pela "inexistência de hierarquia ou diferença de qualidade jurídica entre as duas formas de constituição de um novo autonomizado núcleo doméstico" (THEODORO JUNIOR, 2016, p. 368).

O art. 693 lista os casos de processos contenciosos aos quais estas normas devem ser aplicadas: ações de divórcios, separação, reconhecimento e extinção da união estável, guarda, visitação e filiação.

Somados a esta vindoura previsão legal, prevê o novel códex processual que tais procedimentos sejam perpassados pela busca de soluções autocompositivas, elencando a mediação e a conciliação como os meios técnicos aptos a desenvolverem uma relação consensual ante as partes envolvidas num litígio familiar.

Leciona o caput do art. 694 do referido diploma que:

Art. 694. Nas Ações de Família, todos os esforços serão empreendidos para a solução consensual da controvérsia, devendo o juiz dispor do auxílio de profissionais de outras áreas do conhecimento para a mediação e conciliação.

Outrora, como bem assevera Claúdio Aparecido Ribas, dá-se nestes casos preferência à mediação, uma vez que:

nas ações que envolvem litígio decorrente do direito de família, a inovação em relação às demais áreas do direito decorre da opção de legislador em impor a mediação como requisito de procedibilidade antecedentes a formação da relação processual, ou seja, a demanda envolvendo tais conflitos somente ingressará a fase litigiosa após a realização de uma ou mais sessões de mediação (RIBAS, 2015, p. 667).

Cabe ressaltar que optou o legislador pela mediação, fato que esta "afigura-se recomendável para situações de múltiplos vínculos, sejam eles familiares, de amizade, de vizinhança, decorrentes de relações comerciais, trabalhistas, entre outros" (BACELLAR, 2011).

Analisando mais afinco o instituto da mediação, no tocante à compreensão dos problemas levados ao seu crivo, percebe-se ser mais amplo o seu campo de atuação, principalmente no tocante à preservação dos vínculos anteriormente existente, estabelecendo os alicerces familiares, base elementar da sociedade.

Defendendo a utilização da mediação nos conflitos de origem familiar, Fernanda Tartuce alude que: 
com a facilitação do diálogo pelo mediador, os sentimentos das partes podem ser enfrentados e compreendidos. Sendo-lhes permitido um espaço apropriado para reflexão e o resgate de suas próprias responsabilidades, os mediandos poderão separar os sentimentos dos reais interesses, deixando para trás o passado e podendo se reorganizar para os tempos futuros (Tartuce, 2016, p.327-328).

A pessoa que orienta os trabalhos de uma sessão de mediação é denominada mediadora, a qual recebe um treinamento específico para atuar ativamente nos centros especializados ou nos tribunais, regularmente cadastrados, que conforme o NCPC, devendo ser auxiliares da justiça (arts.165 e 166).

De forma assertiva, Márcia Terezinha Amaral nos ensina que:

a pessoa que conduz a mediação é denominada mediador, o qual é um terceiro imparcial que promove o diálogo entre as partes, mediante a redução das hostilidades, buscando encontrar uma solução ao conflito que satisfaça os interesses e as necessidades de ambas, mas o mediador seja imparcial no que se refere ao relacionamento com as partes e neutro quanto à essência das questões (AMARAL, 2009, p.99).

Prevê ainda o caput do art. 964 que o juiz poderá dispor "do auxílio de profissionais de outras áreas de conhecimento para a mediação e conciliação".

A este dispositivo, Fernada Tartuce esclarece que:

a requerimento das partes ou do mediador, e com anuência daqueles, poderão ser admitidos outros mediadores para funcionar no mesmo procedimento quando isso for recomendável em razão da natureza e da complexidade do conflito (Lei n.13.140/2015, art. 15). Recomenda-se a atuação conjunta, por exemplo, quando se revelar pertinente contar com facilitadores de diferentes gêneros e formações (Tartuce 2016, p.329).

Ainda dando maior visibilidade aos meios alternativos para a resolução dos conflitos, o art. 695 descreve, que, "recebida a petição inicial, e se for o caso, tomadas as providências referentes à tutela provisória, o juiz ordenará a citação do réu para comparecer à audiência de mediação e conciliação, observado o disposto no art. 694".

Interessante observar que o legislador, nos casos específicos das Ações de Família, não cita o réu para contestar, mas sim, para comparecer a uma audiência inaugural de mediação, buscando com este passo, desvencilhar as partes de suas armaduras e tratar de forma mais harmoniosa o impasse entre os litigantes.

Diferentemente do que ocorre no $\S 4$, , inciso I do artigo 334 do CPC, onde a audiência de conciliação ou mediação somente ocorrerá se ambas as partes assim concordarem, nas ações de família, essa audiência é obrigatória. Não obedecendo, algumas das partes, ao mandamento legal, deixando de comparecer ao encontro infra-agendado, tal conduta pode ser considerada ato atentatório à dignidade da justiça (CPC, art. 77, § 1으).

Avançando ainda mais nos moldes da consensualidade, o § 10 do art. 695 assim dispõe: "O mandado de citação conterá apenas os dados necessários à audiência e deverá estar desacompanhado de cópia da petição inicial, assegurado ao réu o direito de examinar seu conteúdo a qualquer tempo".

De forma exímia, Evandro Lima e Samantha Pelajo dissertam que: 
outro sensível avanço legislativo diz respeito à previsão de que, nas Ações de Família, a contrafé (cópia da petição inicial) não mais instruirá o mandado de citação. Com isso, evita-se que a parte, ao ser citada, tenha seu ânimo de beligerância acirrado em razão dos fatos e/ou argumentos expostos na demanda e, com isso, "entrincheire-se" ao até mesmo "armese" como se estivesse numa verdadeira batalha. Comumente, tais petições são redigidas em termos técnicos e, muitas vezes, bastante agressivos - o que se lamenta. Isso contribui sobremaneira para agravar o conflito, pois não gera receptividade no citando; ao revés, provoca-lhe mais mágoa, ressentimento, rancor, ira, frustração, dificultando ou impedindo qualquer diálogo superveniente (LIMA; PELAJO, 2015, p. 238).

De modo contrário, Fernanda Tartuce, não faz reverência ao que preleciona o $\$ 1$ 을 do art. 695, arguindo que:

a regra, porém, desafia a Constituição Federal: ao permitir que apenas uma das partes tenha ciência do que foi apresentado ao juiz, ela promove um desequilíbrio anti-isonômico no processo; se uma das partes apresentou sua versão em juízo, é decorrência do contraditório que haja sua cientificação. Espera-se que os magistrados deixem de dar atenção à regra e promovam a citação atendendo o padrão tradicional de fazer acompanhar o mandado a contrafé (TARTUCE, 2016, p. 330).

A nosso ver, positiva foi a inovação do legislador neste ponto, aparentemente não ferindo nenhum dispositivo constitucional, uma vez que é assegurado ao réu examinar o seu conteúdo a qualquer tempo, ainda mais em tempos de processo eletrônico, onde os autos, quando não estiverem em segredo de justiça, estarão à disposição dos procuradores das partes, em qualquer situação ou lugar.

Ainda versando sobre a audiência de mediação ou conciliação nas Ações de Família, prevê o art. 696 que estas "poderão dividir-se em tantas sessões quantas sejam necessárias para viabilizar a solução consensual, sem prejuízo de providências jurisdicionais para o perecimento do juízo".

Tal previsão é perfeitamente adequada às ações de cunho familiar, pois infere-se que apenas uma reunião não seja suficiente para exaurir todo o assunto pertinente à contenda, podendo facilmente ser designadas sessões sucessivas, para o completo deslinde da causa.

\section{CONCLUSÃO}

Amparado por uma tendência mundial, o legislador brasileiro, vistoriado pelos operadores do direito, incluiu na vida prática jurisdicional, com a entrada em vigor do $\mathrm{CPC} / 15$, a possibilidade de se tratarem os conflitos entre os apartes, de forma consensual, dirigidos por mecanismos que possibilitam o alcance da resolução dos problemas por meio da negociação.

Desta feita, o instituto da mediação se amolda substancialmente nas ações de natureza familiar, possibilitando aos envolvidos, a capacidade de restaurarem seus laços, ou encontrarem a melhor solução para situação que os envolvem.

Assertiva, em compasso, vem se mostrando a utilização dos meios alternativos para a resolução de conflitos, que a seu tempo, trará bons resultados e satisfações ao jurisdicionado brasileiro. 


\section{REFERÊNCIAS}

AMARAL, Marcia Therezinha Gomes do. $\mathbf{O}$ direito de acesso à justiça e a mediação. São Paulo: Lumem Juris, 2009. p. 91.

LIMA, Evandro Souza e; PELAJO, Samantha. A mediação nas Ações de Família. In. ALMEIDA, Diogo Assumpção Rezende de Almeida; PANTOJA, Fernanda Medina;

MARTINS, Sérgio Pinto. Direito Processual do Trabalho. 38. ed. São Paulo: Editora Saraiva, 2016.

PELAJO, Samantha (coords.) A mediação no novo código de processo civil. Rio de Janeiro: Forense, 2015. p. 238.

SILVA, Claudio Aparecido Ribas da. Mediação e conciliação no novo código de processo civil: visão geral e nas ações de direito de família. In. SANTANA, Alexandre Ávalo; NETO, José de Andrade. Novo CPC análise doutrinária sobre o novo direito processual brasileiro. Campo Grande: Contemplar, 2015. p. 667.

TARTUCE, Fernanda. Mediação nos conflitos civis. 2. ed., rev., atual. e ampl. Rio de Janeiro: Forense; São Paulo: Método, 2016.

THEODORO JUNIOR, Humberto. Curso de Direito Processual Civil - Procedimentos Especiais - vol. II - 50a ed. rev., atual. e ampl. Rio de Janeiro: Forense, 2016.

WAMBIER, Tereza Arruda Alvim; [et al]. Primeiros cometários ao novo código de processo civil: artigo por artigo. 1. ed. São Paulo: Editora revista dos Tribunais, 2015. p. 694.

BRASIL, Lei 13.105, de 16 de março de 2015. Disponível: http://www.planalto.gov.br/ccivil 03/ ato2015-2018/2015/lei/l13105.htm. Acesso 15 ago. 2016.

Lei 13.140, de 26 de junho de 2015. Disponível: http://www.planalto.gov.br/ccivil 03/ Ato2015-2018/2015/Lei/L13140.htm. Acesso 15 ago. 2016.

Conselho Nacional de Justiça, Resolução no 125, de 29 de novembro de 2010. Disponível em: http://www.cnj.jus.br/busca-atos-adm?documento=2579. Acesso 15 ago. 2016.

CAPELLETTI, Mauro; GARTH, Byant (tradução: Ellen Gracie Nothfleet). Acesso à Justiça, Porto Alegre: Sergio Antonio Frabris Editor, 1988.

DIDIER Jr., Fredie. Curso de Direito Processual Civil. 18 ed. Salvador: Jus Podvim, 2015.

NERY JUNIOR, Nelson; NERY, Rosa Maria de Andrade. Código de processo civil comentado, 16a ed. rev. atual. e ampl. São Paulo: Editora Revista dos Tribunais, 2016.

NERY JUNIOR, Nelson; NERY, Rosa Maria de Andrade. Leis civis e processuais civis comentadas, 4 a ed. rev. atual. e ampl. São Paulo: Editora Revista dos Tribunais, 2015. 
NETTO, Fernando Gama de Miranda; SOARES, Irineu Carvalho de Oliveira. Princípios procedimentais no novo código de processo civil. In: ALMEIDA, D. A.R. de; PANTOJA, F. M.; PELAJO, S. A mediação no novo código de processo civil. Rio de Janeiro: Forense, 2015.

SANTANNA, Ana Carolina Squadri; VERAS, Cristina Vianna; MARQUES, Giselle Picorelli Yacoub. Independência e imparcialidade: princípios fundamentais da mediação. In: ALMEIDA, D. A.R. de; PANTOJA, F. M.; PELAJO, S. A mediação no novo código de processo civil. Rio de Janeiro: Forense, 2015.

SILVA, José da Silva. Curso de direito constitucional positivo, 33a ed. São Paulo: Malheiros, 2010.

TARTUCE, Fernanda. Mediação nos conflitos civis, 3. ed., rev., atual. e ampl., Rio de Janeiro: Forense; São Paulo: MÉTODO: 2016. 